\title{
Use of Handheld Versus Standard Ultrasound Devices in Ultrasound Rotation at the Emergency Department
}

\author{
Kamonwon lenghong ${ }^{1}$, Kotchakorn Jumroenketpratheep ${ }^{2}$, Somsak Tiamkao ${ }^{3}$, Korakot Apiratwarakul ${ }^{1 *}$ \\ ${ }^{1}$ Department of Emergency Medicine, Faculty of Medicine, Khon Kaen University, Khon Kaen, Thailand; ${ }^{2}$ Department of Sports \\ Medicine, College of Sports Science and Technology, Mahidol University, Nakhon Pathom, Thailand; ${ }^{3}$ Department of Medicine, \\ Faculty of Medicine, Khon Kaen University, Khon Kaen, Thailand
}

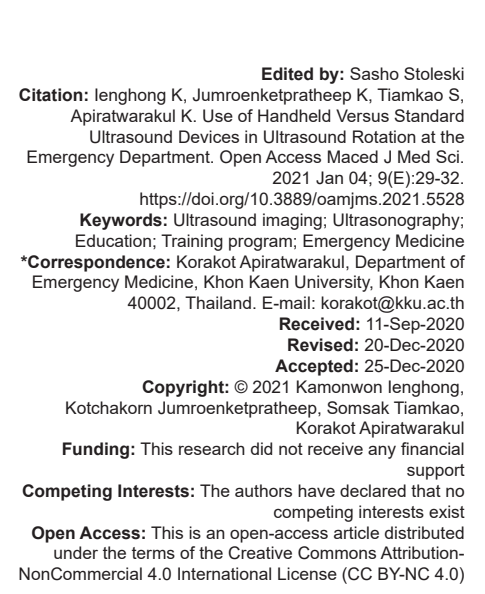

\section{Introduction}

Point-of-care ultrasound (POCUS) is an essential procedure in the emergency department that aids in diagnosis and in performing (particularly invasive) emergency procedures. The use of ultrasound is currently part of residency training in many medical schools. In emergency medicine, POCUS is a core competency in terms of both training and practice.

However, POCUS education depends on the availability of instruments and experts to act as supervisors [1], [2]. Most medical schools with curricula that include POCUS training use standard ultrasound machines, as they tend to produce higher-quality images and have higher ultrasound function. However, these machines can be prohibitively expensive for some programs. Due to its low cost, small size, portability, and suitability for bedside procedures, the handheld ultrasound is now commonly used in emergency departments [2], [3], [4].

In Thailand, however, the handheld ultrasound is a novel technology and there have been no studies examining its use in the training of emergency medicine residents. In this study, we aimed to compare the training experiences of emergency medical residents using handheld versus standard ultrasound machines.

\section{Methods}

\section{Study design}

This was a cross-sectional, single-center, and analytical study in a tertiary university hospital in Thailand. Ethical approval was provided by the Khon Kaen University Ethics Committee for Human Research, and the study was registered with the Thai Clinical Trials Registry (HE631274).

\section{Participants}

Emergency medicine residents at the Khon Kaen University Faculty of Medicine Emergency Medicine Department on their ultrasound rotation 
were enrolled to this study. No monetary incentive was provided. Written informed consent was obtained from each participant before enrollment.

\section{Sample size}

We included all emergency medicine residents on their ultrasound rotation between July 2019 and May 2020.

\section{Ultrasound curriculum}

The ultrasound curriculum at the Khon Kaen University Emergency Medicine Department was first introduced in July 2019 as part of the program for $1^{\text {st }}$-year residents (however, non- $1^{\text {st }}$-year residents may also choose to participate). It consists of a 2-week rotation at the emergency department, during which we provide instruction in the use of both handheld and standard ultrasound machines. Residents also train in bedside ultrasound with a supervisor who is a specialist in POCUS, the journal club, reviewing of ultrasound images, topics included a basic introduction to ultrasound technology, cardiac, lung, abdomen, inferior vena cava (IVC), aorta, and ultrasound protocols such as FAST examination, RUSH protocol, and CASA protocol.

\section{Ultrasound equipment}

The handheld ultrasound machine used was the Butterfly IQ (2D array, 9000 micro-machined sensors, USA). Images can be obtained in B, M, color Doppler, and power Doppler mode. Presets include cardiac, cardiac deep, abdomen, abdomen deep, aorta and gall bladder, lung, FAST, vascular, musculoskeletal, nerve, obstetric, small organ, and pediatric.

The standard ultrasound machine was the Mindray M9, which is the model we use in the emergency department. Images can be obtained in B, M, color Doppler, and power Doppler mode. In addition, there are more cardiac ultrasound functions such as Tissue Doppler Imaging. We provided curvilinear, linear, and phased array probes.

\section{The evaluation}

During their 2-week ultrasound rotation, the participants trained using both standard and handheld machines. At the end of their rotation, they took a selfadministered using a 5-point Likert scale via Google Forms. An email containing a link to the survey was sent to each participant. The survey consisted of 25 questions about participants' experiences using the two devices. The survey and collected data were host by emergency medicine department. To ensure anonymity, yet allow contact with non-responders, each participant was given access to a personalized but de-identified online survey. Two email reminders were sent to non-responders over a period of 1 week to encourage survey completion.

The primary outcome of this study was participants' experience using the handheld versus standard ultrasound in their training.

\section{Statistical analysis}

Mean Likert scale values and standard deviations (SDs) for each electronic survey response were used to represent overall participant agreement. Participant perceptions were presented as frequencies with percentages. Responses were summarized into five categories to reflect agreement: Strongly agree (5), agree (4), neutral (neither agree nor disagree) (3), disagree (2), and strongly disagree (1). An independent sample t-test was used for statistical comparisons, with two-tailed $p<0.05$ being considered statistically significant. All data analyses were performed using Stata version 10.1 (StataCorp, College Station, TX).

\section{Results}

During the period from July 2019 to May 2020 , we had a total of 17 first $(n=7)$, second $(n=5)$, and $3^{\text {rd }}$ year $(n=5)$ emergency medicine residents on ultrasound rotation, $52.94 \%(n=9)$ of whom were male. The average number of scans was 5-10 times/week/ person (Table 1). The response rate was $100 \%(n=17)$.

Table 1: Participant characteristics

\begin{tabular}{ll}
\hline Characteristics & $\mathrm{n}(\%)$ \\
\hline Sex & $9(52.94)$ \\
$\quad$ Male & $8(47.06)$ \\
$\quad$ Female & \\
Year of residency & $7(41.18)$ \\
$1^{\text {st }}$-year & $5(29.41)$ \\
$2^{\text {nd }}$-year & $5(29.41)$ \\
$3^{\text {rd }}$-year & \\
Number of scans per week per person & $6(35.29)$ \\
$5-10$ & $6(35.29)$ \\
$11-15$ & $0(0)$ \\
$16-20$ & $4(23.53)$ \\
$21-25$ & $1(5.88)$ \\
$>25$ & \\
\hline
\end{tabular}

We asked participants to rate their enjoyment of the experience, its accessibility, their improvement with regard to scanning ability and image interpretation, the usefulness of ultrasound rotation (short learning experience), and the usefulness of the emergency medicine residency program (longitudinal learning experience). Agreement was high across all items in with regard to both the handheld and standard ultrasound devices (mean score $>4$ ). Participants rated the handheld ultrasound as being more enjoyable and accessible but not to a statistically significant extent (Table 2).

Participants were also asked to rate the ease of obtaining images and image quality with each 
Table 2: Likert scores pertaining to learning experience in each device

\begin{tabular}{llll}
\hline Learning experience & \multicolumn{2}{l}{ Likert score, Mean \pm SD } & p-value \\
\cline { 2 - 3 } & Standard us & Handheld us & \\
\hline Enjoyable & $4.53 \pm 0.72$ & $4.76 \pm 0.42$ & 0.259 \\
Accessible & $4.59 \pm 0.71$ & $4.82 \pm 0.38$ & 0.244 \\
Improved scanning ability & $4.82 \pm 0.39$ & $4.76 \pm 0.55$ & 0.726 \\
Improved image interpretation ability & $4.71 \pm 0.59$ & $4.71 \pm 0.46$ & $>0.999$ \\
Usefulness as part of a short learning & $4.82 \pm 0.39$ & $4.88 \pm 0.32$ & 0.641 \\
experience & & & \\
Usefulness in longitudinal learning & $4.71 \pm 0.59$ & $4.71 \pm 0.46$ & $>0.999$ \\
\hline
\end{tabular}

Usefulness in longitudinal learning SD: Standard deviation.

device in each of eight views: cardiac, lung, abdomen, kidney and urinary bladder (KUB), obstetrics and gynecology, soft tissue, vascular, aorta, and IVC. Participants rated the standard ultrasound machine higher in terms of ease of obtaining most cardiac views, except for the apical four-chamber view. However, they rated the ease of the handheld device higher for assessing soft tissue and vascular views, though this difference was not statistically significant (Table 3).

Table 3: Likert scores pertaining to ease of obtaining images in each device

\begin{tabular}{|c|c|c|c|}
\hline \multirow[t]{2}{*}{ Ultrasound views } & \multicolumn{2}{|c|}{ Ease of obtaining image Likert score; Mean \pm SD } & \multirow[t]{2}{*}{$p$-value } \\
\hline & Standard us & Handheld us & \\
\hline \multicolumn{4}{|l|}{ Cardiac } \\
\hline PSLX view & $3.71 \pm 0.69$ & $3.53 \pm 0.78$ & 0.495 \\
\hline PSX view & $3.47 \pm 0.62$ & $3.35 \pm 0.76$ & 0.632 \\
\hline Subcostal view & $3.53 \pm 0.85$ & $3.24 \pm 0.73$ & 0.301 \\
\hline $\begin{array}{l}\text { Apical four chamber } \\
\text { view }\end{array}$ & $2.76 \pm 0.64$ & $3.18 \pm 0.62$ & 0.074 \\
\hline Abdomen & $3.94 \pm 0.93$ & $3.94 \pm 0.73$ & $>0.999$ \\
\hline Lung & $3.94 \pm 0.87$ & $3.88 \pm 0.68$ & 0.833 \\
\hline OB-GYN & $3.29 \pm 0.67$ & $3.24 \pm 0.55$ & 0.786 \\
\hline KUB & $3.76 \pm 0.81$ & $3.65 \pm 0.59$ & 0.641 \\
\hline Soft tissue & $3.47 \pm 0.78$ & $3.82 \pm 0.78$ & 0.210 \\
\hline Vascular & $3.12 \pm 0.76$ & $3.65 \pm 0.90$ & 0.082 \\
\hline Aorta and IVC & $3.65 \pm 0.76$ & $3.65 \pm 0.59$ & $>0.999$ \\
\hline
\end{tabular}

In terms of image quality, participants rated the standard device higher for cardiac views and the handheld device higher for soft tissue and vascular views. However, these differences were not statistically significant (Table 4).

Table 4: Likert scores pertaining to image quality in each device

\begin{tabular}{|c|c|c|c|}
\hline \multirow[t]{2}{*}{ Ultrasound views } & \multicolumn{2}{|c|}{ Image quality Likert score; Mean \pm SD } & \multirow[t]{2}{*}{$\mathrm{p}$-value } \\
\hline & Standard us & Handheld us & \\
\hline Cardiac & $3.82 \pm 0.78$ & $3.71 \pm 0.57$ & 0.631 \\
\hline Abdomen & $4.06 \pm 0.80$ & $4.06 \pm 0.80$ & $>0.999$ \\
\hline Lung & $4.06 \pm 0.80$ & $4.18 \pm 0.78$ & 0.678 \\
\hline OB-GYN & $3.47 \pm 0.78$ & $3.65 \pm 0.84$ & 0.540 \\
\hline KUB & $3.94 \pm 0.80$ & $3.94 \pm 0.73$ & $>0.999$ \\
\hline Soft tissue & $3.88 \pm 0.68$ & $4.12 \pm 0.83$ & 0.386 \\
\hline Vascular & $3.88 \pm 0.83$ & $4.00 \pm 0.77$ & 0.680 \\
\hline Aorta and IVC & $4.00 \pm 0.91$ & $4.00 \pm 0.77$ & $>0.999$ \\
\hline
\end{tabular}

In terms of the device qualification, the handheld device scored higher in all areas. Moreover, the handheld device was rated significantly higher in terms of convenience in bedside procedures and usefulness to the patient (Table 5).

Table 5: Likert scores pertaining to device qualification

\begin{tabular}{llll}
\hline Device qualification & \multicolumn{2}{l}{ Likert score; Mean \pm SD } & p-value \\
\cline { 2 - 3 } & Standard us & Handheld us & \\
\hline Ease of use & $4.18 \pm 0.73$ & $4.41 \pm 0.49$ & 0.282 \\
Convenience & $3.94 \pm 0.81$ & $4.53 \pm 0.70$ & 0.034 \\
Usefulness for the patient & $3.82 \pm 0.86$ & $4.82 \pm 0.38$ & $<0.001$ \\
\hline SD: Standard deviation & & &
\end{tabular}

\section{Discussion}

This study found no significant difference between handheld standard ultrasound machines in terms of the learning experience. Nevertheless, participants rated the handheld device as being easy to access and enjoyable. This is consistent with the results of a study of Galusko et al. [5], which found teaching medical students the basics of ultrasound using novel handheld devices to be feasible and effective. It is likely that the size and portability of the devices made learning in a crowded emergency department easier. Both short- and long-term learning scores for the two devices were similar in our study. However, a study by Ireson et al. [6] conducted in $1^{\text {st }}$-year anatomy students found that the handheld device was easy to use and beneficial for insonation training as a part of the longitudinal learning experience across all school years.

Participants in our study rated the standard ultrasound as easier in terms of both obtaining cardiac images and cardiac image quality. Previous studies [7], [8], [9], [10], [11], [12] have reported high levels of confidence in using the handheld ultrasound device to obtain cardiac images, even after short training sessions but did not report on image quality. The handheld ultrasound we used in this study has only one transducer to obtain all image views, which was wider than the standard echocardiography probe, making it difficult to access the patient's rib space to obtain an image. The handheld ultrasound, however, received higher scores for soft tissue and vascular images in terms of both ease and quality. Most studies about vascular ultrasound focused on ultrasoundguided peripheral intravenous access, for which they recommended a handheld device [13], [14], [15], [16]. They did not, however, report on ease of obtaining images or image quality.

Participants rated the handheld ultrasound as being useful and convenient. This was consistent with a study by Shokoohi et al. [17], which found that $70 \%$ of clinical educators reported using POCUS very frequently or often in aiding diagnosis, $45 \%$ used POCUS frequently or often in determining treatment, $31 \%$ used POCUS in monitoring the clinical course of patients, and $16 \%$ reported frequent use of POCUS for the procedural applications.

This was the first study to examine the use of handheld ultrasound devices in an emergency medicine residency ultrasound rotation. It was limited in that we had only one handheld device, meaning that these findings may not be generalizable to other types/brands. Another limitation was the small sample size [18], [19], [20], [21], [22], which was due to limitations in the number of teachers, ultrasound devices, and residents on this rotation. 


\section{Conclusion}

These findings suggest that handheld ultrasound devices can be beneficial as learning tools for emergency medicine residents. Participants enjoyed the learning experience and felt that these devices were useful for patients and made it convenient to perform the procedure.

\section{Acknowledgments}

The authors would like to thank all participants in this study and Dylan Southard for acting as English consultant.

\section{References}

1. Whitson MR, Mayo PH. Ultrasonography in the emergency department. Crit Care 2016;20(1):227.

PMid:27523885

2. Coşkun F, Akıncı E, Ceyhan MA, Sahin Kavaklı H. Our new stethoscope in the emergency department: handheld ultrasound. Ulus Travma Acil Cerrahi Derg 2011;17(6):488-92. https://doi.org/10.5505/tites.2011.89914 PMid:22289999.

3. Hatfield A, Bodenham A. Portable ultrasound for difficult central venous access. $\mathrm{Br} \mathrm{J}$ Anaesth 1999;82(6):822-6. https://doi. org/10.1093/bja/82.6.822 PMid:10562772.

4. Ault MJ, Tanabe R, Rosen BT. Peripheral intravenous access using ultrasound guidance: Defining the learning curve. JAVA 2015;20:32-6. https://doi.org/10.1016/j.java.2014.10.012

5. Galusko V, Khanji MY, Bodger O, Weston C, Chambers J, lonescu A. Hand-held ultrasound scanners in medical education: A systematic review. J Cardiovasc Ultrasound 2017;25(3):7583. https://doi.org/10.4250/jcu.2017.25.3.75 PMid:29093769

6. Ireson M, Warring S, Medina-Inojosa JR, O'Malley MT, Pawlina W, Lachman N, et al. First year medical students, personal handheld ultrasound devices, and introduction of insonation in medical education. Ann Glob Health 2019;85:1-6. https://doi.org/10.5334/aogh.2565

7. Cawthorn TR, Nickel C, O'Reilly M, Kafka H, Tam JW, Jackson LC, et al. Development and evaluation of methodologies for teaching focused cardiac ultrasound skills to medical students. J Am Soc Echocardiogr 2014;27(3):302-9. https://doi. org/10.1016/j.echo.2013.12.006 PMid:24433979.

8. Fox JC, Schlang JR, Maldonado G, Lotfipour S, Clayman RV. Proactive medicine: The " $\mathrm{UCl} 30$, , an ultrasound-based clinical initiative from the University of California, Irvine. Acad Med 2014;89(7):984-9. https://doi.org/10.1097/ acm.0000000000000292 PMid:24826849

9. Mai TV, Ahn DT, Phillips CT, Agan DL, Kimura BJ. Feasibility of remote real-time guidance of a cardiac examination performed by novices using a pocket-sized ultrasound device. Emerg Med Int 2013;2013:627230. https://doi.org/10.1155/2013/627230 PMid:24024032

10. Stokke TM, Ruddox V, Sarvari SI, Otterstad JE, Aune E, Edvardsen T. Brief group training of medical students in focused cardiac ultrasound may improve diagnostic accuracy of physical examination. J Am Soc Echocardiogr 2014;27(11):1238-46. https://doi.org/10.1016/j.echo.2014.08.001 PMid:25216765.

11. Andersen GN, Viset A, Mjølstad OC, Salvesen O, Dalen $H$, Haugen BO. Feasibility and accuracy of point-of-care pocketsize ultrasonography performed by medical students. BMC Med Educ 2014;14:156. https://doi.org/10.1186/1472-6920-14-156 PMid:25070529

12. Gogalniceanu P, Sheena Y, Kashef E, Purkayastha S, Darzi A, Paraskeva P. Is basic emergency ultrasound training feasible as part of standard undergraduate medical education? J Surg Educ 2010;67(3):152-6. https://doi.org/10.1016/j.jsurg.2010.02.008 PMid:20630425.

13. Moore CL, Copel JA. Point-of-care ultrasonography. N Engl J Med 2011;364(8):749-57.

PMid:21345104

14. Laksonen RP Jr., Gasiewicz NK. Implementing a program for ultrasound-guided peripheral venous access: Training, policy and procedure development, protocol use, competency, and skill tracking. Nurs Clin North Am 2015;50(4):771-85. https://doi. org/10.1016/j.cnur.2015.07.010 PMid:26596664.

15. Lian A, Rippey JC, Carr PJ. Teaching medical students ultrasound-guided vascular access which learning method is best? J Vasc Access 2017;18(3):255-8. https://doi.org/10.5301/ jva.5000730 PMid:28430318.

16. Oliveira L, Lawrence M. Ultrasound-guided peripheral intravenous access program for emergency physicians, nurses, and corpsmen (technicians) at a military hospital. Mil Med 2016;181(3):272-6. https://doi.org/10.7205/milmed-d-15-00056 PMid:26926753

17. Shokoohi H, Raymond A, Fleming K, Scott J, Kerry V, HaileMariam $\mathrm{T}$, et al. Assessment of point-of-care ultrasound training for clinical educators in Malawi, Tanzania and Uganda. Ultrasound Med Biol 2019;45(6):1351-7. https://doi. org/10.1016/j.ultrasmedbio.2019.01.019 PMid:30904246

18. Apiratwarakul $\mathrm{K}$, Pumiyoch $\mathrm{P}$, lenghong $\mathrm{K}$, Phungoen $\mathrm{P}$ Gaysonsiri D, Bhudhisawasdi V. Endotracheal intubation on a stationary vs. moving ambulance. J Med Assoc Thai 2020;103:18-21.

19. lenghong $\mathrm{K}$, Ussahgij $\mathrm{W}$, Kanthachat $\mathrm{K}$, Apiratwarakul $\mathrm{K}$ Phungoen P, Bhudhisawasdi V. Factors associated with severe intracranial pathology in acute non-traumatic headache patients in the emergency department. J Med Assoc Thai 2020;103:47-50.

20. Apiratwarakul K, lenghong $K$, Gaysonsiri $D$, Mitsungnern $T$, Buranasakda M, Bhudhisawasdi $\mathrm{V}$. The effectiveness of oxygen-powered inhalation devices in prehospital care. J Med Assoc Thai 2020;103:58-60.

21. lenghong $K$, Kleebbuakwan $K$, Apiratwarakul $K$, Phungoen $P$, Gaysonsiri D, Bhudhisawasdi V. Comparison of cleaning methods for ultrasound probes at an emergency department in a resource-limited country. J Med Assoc Thai 2020;103:67-71.

22. Apiratwarakul $\mathrm{K}$, Songserm $\mathrm{W}$, lenghong $\mathrm{K}$, Phungoen $\mathrm{P}$, Gaysonsiri D, Bhudhisawasdi V. The role of mechanical cardiopulmonary resuscitation devices in emergency medical services. J Med Assoc Thai 2020;103:98-101. 